Portland State University

PDXScholar

\title{
Arabic Diglossia within Palestinian-Arab Folk Narratives
}

Jordan M. Martinez

Portland State University

Follow this and additional works at: https://pdxscholar.library.pdx.edu/honorstheses

\section{Let us know how access to this document benefits you.}

\section{Recommended Citation}

Martinez, Jordan M., "Arabic Diglossia within Palestinian-Arab Folk Narratives" (2017). University Honors Theses. Paper 421.

https://doi.org/10.15760/honors.417

This Thesis is brought to you for free and open access. It has been accepted for inclusion in University Honors Theses by an authorized administrator of PDXScholar. Please contact us if we can make this document more accessible: pdxscholar@pdx.edu. 


\section{ARABIC DIGLOSSIA \\ WITHIN PALESTINIAN-ARAB FOLK NARRATIVES}

Jordan Martinez

Dr. Dirgham H. Sbait

Honors 403: Undergraduate Thesis

June 15, 2017 


\section{Acknowledgements}

I would like to give a special thanks to my thesis advisor, Dr. Sbait, for spending numerous hours working with me this past year. This project would have been impossible without his guidance and profound knowledge of the Arabic language. I wish you luck in your retirement! I would also like to acknowledge the work put forth by Ibrahim Muhawi and Sharif Kanaana. Their work with Speak Bird, Speak Again is unprecedented, and will always be appreciated. 


\begin{abstract}
The preservation of Palestinian folktales is a way to restore and preserve Palestinian culture in result to the declining state and displacement of Palestinian populations into other regions of the Arabic World (Muhawi and Kanaana 1989). Some academics have acknowledged that the translation of folklore and other similar tales have contributed to a growing consideration of foreign cultures and the overall understanding by non-native sources (Klaus Roth 1998) (Kanaana 2005). Throughout this paper, I analyze the work put forth by Ibrahim Muhawi and Sharif Kanaana and their success in transcribing and translating a collection of folk narratives in their original form.

Throughout this paper I effectively fill the sociolinguistic gap within Speak Bird Speak Again, by highlighting and commenting on occurrences of Arabic diglossia within the text. This compliments the anthropological and minimal linguistic approach within the authors' own analysis. Within my work I answer the questions: how does the complexities of Arabic diglossia influence the translation, transcription, and the anthropological understanding of these Palestinian folk tales from the perspective of a non-native Arabic learner? This research shows the multifaceted dimensions within the Arabic language and elucidates on why Muhawi, and Kanaana's anthropological commentary is presented in Speak Bird Speak Again. Through the analysis of Spoken Palestinian Arabic juxtaposed to Modern Standard Arabic, I was able to expound upon cultural implications which are introduced in the text. Moreover, this approach further aids in the linguistic and cultural comprehension of Palestinian folk narratives from the perspective of non-native Arabic learners.
\end{abstract}




\section{Introduction}

The aim of this paper is to highlight Arabic diglossia within Palestinian folktales by means of producing a sociolinguistic commentary on Ibrahim Muhawi and Sharif Kanaana's Speak Bird, Speak Again. In a report published by the School for International Training (SIT), Arabic diglossia is defined as a sociolinguistic phenomenon composed of two different variations of Arabic spoken within the same speech community, a higher-level Arabic used for written and special occasions, and a lower-level Arabic, used for communicative purposes (Al-Mamari 2011). A prime example would be Modern Standard Arabic (high) juxtaposed to Spoken Palestinian Arabic (low). Furthermore, variations of Spoken Arabic are influenced by various regional, ethnic, and social groupings. (Tiedemann 2015). So consequently, the multifaceted complications due to Arabic diglossia inhibit the ability to learn the language from the perspective of a non-native speaker. Therefore, I believe that examining Arabic diglossia by relating linguistic components with cultural-specific characteristics can aid in the comprehension process of non-native Arabic learners.

Through a selection of 3 folktales: "Ṭunjur, Țunjur", "The Precious One and the WornOut One", and "The Green Bird"1: I shall select specific language that demonstrates the presence of Arabic diglossia while using the English variant ${ }^{2}$ as an aid in the sociolinguistic and translation analysis. Each of these narratives serve as a valuable representation of Palestinian culture and common language due to their authenticity ${ }^{3}$. I shall first present a brief historical and linguistic review on Arabic diglossia. Then, I shall investigate Arabic diglossia’s societal and

\footnotetext{
${ }^{1}$ Additionally, several folk tales throughout "Speak Bird, Speak Again" are commonly narrated within other geographical regions and are not culturally grounded to Palestinian culture.

2 "Speak Bird, Speak Again" was also published in French, in addition to English and Arabic.

${ }^{3}$ Each story throughout "Speak Bird, Speak Again" (Muhawi and Kanaana 1989) were transcribed and translated into their original spoken form.
} 
linguistic characteristics within selected passages. The comprehensive analysis of chosen language shall concentrate on distinctions between Modern Standard Arabic (MSA from now on) and Spoken Palestinian Arabic (SPA from now on).

Arabic folktales are told in the given geographical language of the narrator. Arguably, there are several distinct spoken Arabic languages and dialects within various regions of the Arab world: North African Maghreb, Libya, Egypt, Al-Sham or Levant (Lebanon, Syria, and Palestine), Iraq, the Gulf, and Yemen are all have their own variation Spoken Arabic and are considered languages by definition (Sbait 2017). Each spoken language can be further defined based on a more distinct area within the expansive regions which are known as dialects. ${ }^{4}$ The cultural and linguistic components in Speak Bird, Speak Again consist of narratives from Palestine (which is identified as Levantine Arabic) and is transcribed in SPA then translated into English. ${ }^{5}$ While the comparison of different regional spoken languages is important for the understanding of Arabic dilgossia, my focus shall remain on SPA and MSA.

Historically, Arabic folktales transpire orally and are passed down through several generations, as opposed to written canonical text (Muhawi and Kanaana 1989). Cultural implications may be interpreted and altered over the years based on interpretations of the given narrators (Muhawi and Kanaana 1989). Historically, folktales are primarily told by women to children; however, there are numerous circumstances where men (mainly older) are involved as a listeners or narrators (Sbait 2017) (Rynolds 2009). ${ }^{6}$ Canonized Arabic folktales typically have a

\footnotetext{
${ }^{4}$ Arab linguists and intellectuals use the expression "dialect" instead of a spoken language, due to a lack of affirmed recognition of the various spoken languages. (Sbait 2017).

${ }^{5}$ Even though Palestine is in the greater Al-Sham region, it can be considered its own language due to the uniqueness of vocabulary. Within Palestine, one could identify further spoken variations given unique pronunciation of words, which may be considered as a "dialect" within the Spoken Palestinian Arabic (Sbait 2017).

${ }^{6}$ From the Epics of the Arabs, professional story tellers would be known as الحكواتي alhakawaati, which were primarily men (Rynolds 2009).
} 
series of motifs and genres that correspond or act symbolically in direct correlation with the culture in which the folktale originated from (Ibrahim Muhawi 1998).

Ibrahim Muhawi is a pioneer in Arabic folklore and translation theory. His work involves ample pieces of Arabic translation along with years of work toward folkloristic translation theory, which is exemplified in (along with Sharif Kanaana) Speak Bird, Speak Again. His is scholarly endeavors have contributed toward a large step forward and continuation in the intellectual understanding and canonical status of Arab folktales. Sharif Kanaana is a professor of sociology and anthropology at Bir Zeit University whose anthropological expertise helped construct the extensive cultural analysis coupled with the translation of folktales in Speak Bird, Speak Again. In short, both scholars have a profound knowledge of the Palestinian culture and language.

Muhawi's transcription and translation of Arabic folk narratives succeeds at introducing a segment of Arab folk literature as true Arabic folktale canon (Ibrahim Muhawi 1998). Hence, within his documented folktales, the translation into English itself has taken its literal form without the cultural dysphoria caused by inaccurate translations to fit within the eyes of western culture, along with the oral tradition which is now transcribed. This has not always existed among other translated and transcribed (or lack thereof) folk literature. "What achieves canonicity in a translated version does not always carry the cultural content of the original" (Ibrahim Muhawi 1998).

Language however, can never be transferred in total synonymy, meaning that translation goes beyond a transfer of text, therefore relying on context and cultural perspectives (Klaus Roth 1998). Sharif Kanaana and Ibrahim Muhawi incorporates a detailed analysis of the stories transcribed within the expansive footnotes, introduction, and conclusion of Speak Bird, Speak 
Again. Their analysis aids in both non-native and native comprehension of Palestinian folktales. However, the multifaceted complications due to Arabic diglossia still inhibit the ability to learn the language from the perspective of a non-native speaker. Therefore, a further elaboration and extension of their anthropological commentary coupled with a linguistic analysis can strengthen text and give the non-native readers a better grasp on SPA.

In this paper, I shall highlight and expand on the anthropological analysis and linguistic clarification put forth by Muhawi, and Kanaana, and then take it even further. I hope to demonstrate comprehension hindrances that coexist within the translation of Muhawi and Kanaana's folk narratives, and how they would be perceived without the key analytical components demonstrated in the text. Additionally, I aim to explain this with a supplementary linguistic and extended anthropological approach. To do this, a separate analysis of selected language demonstrating Arabic diglossia and chosen from a variety of folk narratives are needed.

\section{Review on Arabic Diglossia}

Diglossia was first acknowledged in English in 1958 written in a paper by Charles A.

Ferguson. Ferguson aimed at describing how two or more varieties of the same language would be used in the same speech community such as a standard language and a common dialect of the region. In fact, "Arabic diglossia can be traced all the way back to the inception of the language itself (Ferguson 1959)”. Ferguson describes two varieties of a language described as H for standard and L for a dialect. In this case $\mathrm{H}$ would be MSA (MSA) and L would be SPA (SPA). Ferguson highlights many complications imposed by diglossia such as functions, prestige, literary heritage, acquisition, standardization, stability, lexicon, and phonology.

However, Arabic diglossia is far more complex than Ferguson's standard-dialect analysis and generalized diglossic complications. A report published by the Journal of Language and Teaching and Research (JLTR) states "classical Arabic is the oldest form of the Arabic language 
we know today" (Mahmoud A. Al-Sobh 2015), therefore allows Arabic diglossia to be analyzed through a synchronic and diachronic cultural perspective ${ }^{7}$. This language has been around for over 2000 years and was primarily spoken in the Hijaz region and Yemen (Mahmoud A. AlSobh 2015). Classical Arabic is considered to be the foundation of the language itself, as all other Arabic languages and dialects are said to derive from this variation ${ }^{8}$ (Mahmoud A. Al-Sobh 2015). MSA is a much closer derivative of Classical Arabic but uses considerably different vocabulary (Alan S. Kaye 1994). MSA and Classical Arabic are both considered Fusha الفصحى Arabic which means the literary form of Arabic. However, MSA is used in a register less complex than classical Arabic. Likewise, MSA contains the same internal vowel structure and phonological emphasis of Classical Arabic, but does not always incorporate the intricacies of every case ending. MSA appears in the writing of Modern Arabic Prose, such as novels, short stories, literary articles, etc. Additionally, MSA presents itself in Modern Arabic Poetry and other formal situations such as television broadcasting, news articles, public speaking, advertisements, etc. (Sbait 2017).

Kaye mentions a form of Arabic similar to MSA known as Educated Spoken Arabic (Alan S. Kaye 1994). ${ }^{9}$ Similar to MSA, Educated Spoken Arabic lacks the intricacies of case endings, but also mixes colloquialisms into their speech. This directly apposes Ferguson's notion that diglossia is a stable phenomenon due to diglossic switching. ${ }^{10}$ On the other hand, SPA would commonly be used in casual settings such as everyday conversations or storytelling (Sbait 2017). This typically (but not always) involves different syntax, phonological, and

\footnotetext{
${ }^{7}$ The diachronic functions of the language influence the synchronic functions of the language today. See (Hudson 2002).

${ }^{8}$ Classical Arabic dates to pre-Islam later revealing itself in the Qur'an, thus aiding in its preservation.

9 Arabs would describe this form of Arabic as لغة المثقفين lughat almuthaqqafin, or the "language of intellectuals".

${ }^{10}$ Diglossic switching is the notion that the H an L presented by Ferguson can be spoken simultaneously (Eid 1996).
} 
morphological changes to the language. However, the majority of words in SPA exist in MSA; very few SPA words have originated without some outside influences from MSA, Classical Arabic, or other languages such as Persian, Turkish, Italian, and French (Sbait 2017).

Ferguson introduced diglossia in English and since then ample work has been done on the topic. Moreover, scholars have found weaknesses in Ferguson's original analysis of diglossia and criticizes it as "putative” and lacking much detail (Fishman 1967) (Maamouri 1998). Ferguson briefly uses an example of Christian and Muslim dialects in his paper to illustrate Arabic diglossia. From my experience as a non-native speaker, I believe that diglossia in the context of MSA, SPA, and other regional varieties provide better examples of diglossia; opposed to Ferguson's notion about varieties within religious communities. My experience with the language, along with living in the Arab world, has proven that one can find a mix of religious peoples living together while speaking the same Arabic language variation. Further research has proven this to be completely accurate and normal (Sbait 2017). Additionally, I have discovered that regional differences are more distinguished than communal varieties within the same region (Sbait 2017). However, while juxtaposing MSA with a regional variety (SPA) is my primary concern; the study of diglossia in terms of dialectology is still, very much prevalent within academia. $^{11}$

A paper published by Joshua Fishman extrapolates on this idea further, through his extended definition of diglossia. He complicates Arabic diglossia by introducing multicultural notions, such that people themselves cannot be classified as diglossic, but is rather identified by

\footnotetext{
${ }^{11}$ It is important to note the difference between Arabic languages and Arabic dialects: both are examples of diglossia, however dialects are primarily phonological changes within the languages, while some scholars argue those regional varieties which incorporate a different lexicon would be considered another Arabic Language rather than simplistically labeling the variation as a 'dialect' (Alan S. Kaye 1994) (Sbait 2017). For more information on Arabic Dialectology see (Rosenhouse 2011).
} 
the behavior of the speech community in which they are in, and that more than two varieties can be used. Fishman defines diglossia as "a variety of languages which show functional distribution in speech community" (Fishman 1967). Even though I plan to narrowly focus on the dichotomy of MSA and SPA, I will also incorporate the societal influences and linguistic changes of the language, as opposed to only focusing on the community of people who use the language.

A growing number of scholars over the years have acknowledged issues among native Arabic speakers such as low literacy and high illiteracy rates in the Arab world. The Senior Researcher and Research Administrator at the Linguistic Data Consortium (LDC), Mohamed Maamouri, tracked the low levels of educational achievement and traced it back to how MSA is taught in formal and informal schooling in 1998. He concurred that these problems exist based on the linguistic complexities and differences between MSA and its colloquial spoken counterpart. Not only that, but the study went on to show extreme social ramifications behind this linguistic phenomenon (Maamouri 1998). Ultimately, he concluded the need for an educational plan and "educational strategies" to tackle Arabic diglossia in the Arab world.

Therefore, the report by JLTR uses the historical context of Arabic to relate the problems with Arabic diglossia through a sociolinguistic analysis and how Arabic is taught and learned by native speakers. This was in hopes to create a plan for closing the gap between colloquial Arabic and Classical Arabic introduced by Maamouri. Similar to using the historical context of the language to close the gap, it is necessary to understand the sociolinguistic qualities of words used throughout Muhawi and Kanaana's Speak Bird, Speak Again. Such as, the etymology of SPA and how the specific words evolve and influence the Palestinian people to use it in the context in which they do. 
Although there has been an ongoing trend and consensus of educational problems that arise due to Arabic diglossia, it appears that little research has been done in relation to the nonnative Arabic speaking perspective and learning process. The School of International Training Graduate Institute (SIT) published a research paper aimed at monitoring how diglossia effects learners of the Arabic language. As expected, they concluded there was indeed a significant impact on non-native Arabic language learners and that the awareness of Arabic diglossia was higher among the more advanced learners. However, this research was a general study to determine its impact on Arabic learners; not focusing on a specific Arabic language.

SIT concluded that majority of the advanced students were more comfortable speaking based off their known goals, such as which dialect they want to learn (Al-Mamari 2011). Clearly, Arabic diglossia poses as an obstacle of intimidation to the ability of learning from a native and non-native Arabic speaking perspective, which is being looked at by many academics (AlMamari 2011) (Fishman 1967) (Maamouri 1998) (Mahmoud A. Al-Sobh 2015).

The following analysis will consist of various words and phrases chosen throughout three narratives: "Tunjur Tunjur", "The Precious One and the Worn-out One”, and "The Green Bird". Each word and phrase demonstrates specific characteristics associated with Arabic diglossia. I shall highlight the juxtaposition between the Palestinian phrase, MSA equivalent, the translation, and my own interpretation of the internal social ramifications within the phrase and few etymological references to help the reader understand the complexities behind SPA, and to show the role in which culture plays within the language itself. 


\section{Analysis}

“Tunjur, Tunjur”: 12

"بطعمنى بنت و لو انها تكون طُجره .... اجا عابالها اولاد ..."

Muhawi and Kanaana use the translation of the phrase اجا عبالها اولاد eja eabalaha 'awlad to mean "urge": "Once upon a day she had an urge; she wanted babies" (Muhawi and Kanaana 1989). Normally in American English, the word "wish" or "desire" is used more appropriately. In western culture the word urge is popularly designated for bodily functions or other urgent subjects of need. This choice of word seems to be commonly used for occurrences that would require immediate action or attention..." urge" could work, but in this case, it sounds odd to the American-English ${ }^{13}$ ear. When اجا عبالها اولاد is translated back into Palestinian Arabic, the literal translation I found was "children came across her mind, or "she thought about having kids"."

In hindsight, I would argue Muhawi intentionally translated this expression in this way to show the importance of having children within Palestinian culture. Within his analysis, Muhawi explains how children are placed at a very high value of importance, largely in part, and due to the Arab Israeli conflict and ethnic cleansing within the region (Muhawi and Kanaana 1989). Therefore, placing the need for children as an urgent matter. I found it interesting the narrator did not use the more accurate word for wish, urge or desire; "رغبه". The narrator may not have meant to make this appear urgent, as Muhawi intended to do; to prove a subtle point. From the perspective of a non-native Arabic learner, this sentence sounds confusing when comparing the translation with the original text.

\footnotetext{
12 The phrase طُنجُر، طُنجُ طنجرة tunjura, meaning pot (Muhawi and Kanaana 1989). This phrase is meant to be playful and funny which makes the folktale more kid friendly.

${ }^{13}$ I use the term American-English because I am not well versed in other English languages or dialects. Much like the word for bathroom, which can be different among multiple English speaking countries.
} 
The state of mind to which "urge" is translated by Muhawi, can be associated with another Palestinian word for "giving" which represents another example of Arabic diglossia. After the phrase "May Allah grant me children", Muhawi explains the colloquial word for "giving" is يطعم yit am, which literally translates to the word "feed" in MSA. For non-native Arabic learnerss, the word يطع appears confusing; especially if one has only ever learned MSA (as most first and second year students have). The MSA equivalent of "giving" is إعطاء $i$ ta'. This is a prime example of complications with Arabic diglossia in which Ferguson highlights; functions and lexicon ${ }^{14}$.

When considering Arab culture, feeding someone is one of the greatest gestures one can partake in (Sbait 2017). Therefore, I argue the etymological movement from يطعم to holds more weight and influence as a word. Additionally, if one were to compare having an "urge to eat" with getting pregnant; this use of the word "urge" would be symbolic toward the meaning of life. For example, Muhawi adds a footnote correlated to the word "feed" explaining how it is used about the Angel Gabriel and his divine will to grant conception. Therefore, Gabriel feeds (grants) a child into a person's life; "If he will feed (grant) me with sons, He does not mistake where my mouth is, and if He shuts me out He does not trouble himself about me" (Muhawi and Kanaana 1989).

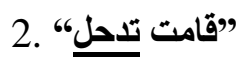

A prime example of Arabic diglossia when referring to lexical differences, appear when the narrator says "قامت تلدل" qamat tadhul, translated as "the pot started to roll". Rather than using the typical MSA word for rolling, تدحرج tadahraj; the narrator of this story says تدحل tadhul (Muhawi and Kanaana 1989). Throughout the بلاد الشام bilad alsham (the Greater Syrian region),

\footnotetext{
${ }^{14}$ See (Ferguson 1959).
} 
the phrase دحلت عجال السياره dahalat eijaal assayarah is used for variations of the meaning "wheels of the car are spinning". The example within the text presents the colloquial verb دحل in

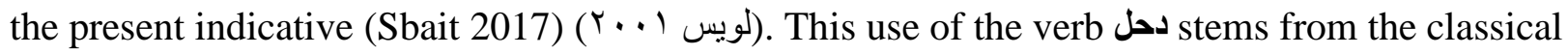
meaning of "to attack". For example, throughout classical Arabic, there is a common expression

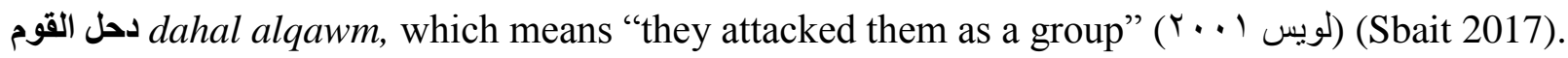
There is another interpretation of the word دحل which means to run away or to hide, therefore used as another meaning of movement (أنيس 1990). The word "spinning" or "rolling" then comes as an extension to these references. If a non-native speaker were only acclimated with MSA, they might misinterpret تدحل for various meanings. Understanding where a word has evolved from, may help the non-native Arabic learner in their ability to comprehend or even retain knowledge about SPA.

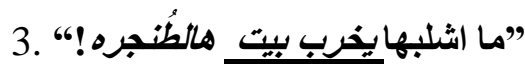

Naturally, figures of speech and metaphors would appear and play a significant role within the Arabic language. The phrase يخرب بيت yakhrib bayt is used and translated as "I'll be damned!” In MSA, this phrase means “may the house of so-and-so be ruined”. This phrase is commonly used to insult one another in SPA by saying "may God ruin your house and family." Insults in Arabic typically hold much more weight than insults in English ${ }^{15}$. If one were to insult your house, they would be insulting not just you, but your entire family. This is culturally connected with the issue of reputation of Palestinian families (Sbait 2017). However, in this case, this phrase was not meant to be used in a derogatory way, but used to exclaim amazement.

\footnotetext{
15 This notion comes from my own experiences of studying the Arab culture and language while living in Jordan
} 
It is important to understand this word and understand the contextual evidence of amazement versus being insulted; especially for the non-native Arabic learners. ${ }^{16}$

\section{4. "ققاموا صارو يمرقو الناس،"}

The phrase قاموا صارو يمرقو الناس qamu saaru yumurqu alnnas was translated into English by Muhawi as "in a while people were passing by". I wish to argue that this translation is grammatically inaccurate. The narrator did not have the intentions of denoting future tense within this context. If they did, then the phrase "In a while people will pass by" makes much more sense, grammatically. Because this phrase is meant to be in the past tense, I found that a more appropriate translation would be, "after a while, people began to pass by". Therefore, Muhawi and Kanaana are a little off. Considering both author's (Muhawi and Kanaana) extensive work with these folktales, this does not detract from their fluency in the English language, and their expert translation ability throughout the rest of the text.

Aside from the small translational error, this sentence may pose other complications for non-native Arabic learners. Because Arabic is a homophonous language by nature, the language becomes very complicated due to the presence of multiple meanings within a single word. ${ }^{17}$ Additionally, when intertwined with the concept of Arabic diglossia, SPA can become more confusing for the non-native speaker. The word يمرقو yamriqu comes from the root مرق maraq or maraqa (Wehr 1994).

For example, per Hans Wehr Dictionary, the most common meaning of this word in MSA is "broth" or "bullion". However, in Classical Arabic, the word مرق means "to go through", such as an arrow passing piercing and passing through an object. Typically, when an Arab hears the

\footnotetext{
${ }^{16}$ Within the text, footnotes on this phrase are only found in the Arabic version. Therefore, adding significance to my work upon making it available to a non-native speaker.

${ }^{17}$ Homophony is a linguistic term which explains how a single word may have multiple meanings. For example, in English we use the word "pen", and "pen" to denote a writing utensil and place for animals to sleep.
} 
term مرق, two meanings come to mind. One of them being "broth", and the other colloquial meaning "to pass by". In SPA, oftentimes Arabs will change the word مرق to sound like marraqha in order to differentiate between meanings (Sbait 2017). In SPA, the word مرق can be used idiomatically, such as "getting away with something", "passed by someone", or "going over someone's head"; such as within the context of naivety (Sbait 2017). Its colloquial meaning is a derivative from the aforementioned classical expression of "passed" or "crossed". Another example in Classical Arabic is مرق رجل مرق و اجتاز maraq rajul maraq wa aishtaza, which means “the man crossed” and passed” (أنبس 1990) (Sbait 2017). Its homophonous characteristics portrayed within both MSA, SPA, and Classical Arabic make the word uniquely difficult for the non-native Arabic learner to understand. However, after looking at the implications from the classical meaning, a non-native Arabic learner may be able to differentiate the intended colloquial meaning apart from the MSA meaning.

There is a third unique quality about this word concerning the phonology of the letter "ق" qaf. This letter in particular is pronounced differently given the specific regional, ethnical, or social grouping of the speaker. For example, some regions throughout the Levant, most Egyptians pronounce the letter "ق" qaf as a $₫$ khamza, which replaces the original "q" sound, with a glottal stop (Sbait 2017). Other groups such as Bedouins or those in the Gulf would pronounce the letter قwith the hard "g" sound, meaning it would replace the heavy original “qaf" sound with a glottal stop (Sbait 2017). ${ }^{18}$ This aspect of diglossia effects the ability to read the SPA after the canonization of the spoken words, but allows one to pick up on the general region a person is from, by the way they pronounce the letter ق.

\footnotetext{
18 This information was obtained from feedback with my thesis advisor, Dirgham H. Sbait, Professor of Arabic language, literature, and folklore at Portland State University. For more information about the letter "ق" qaf see Apendix $B$.
} 


\section{5وفي يا مره هالطُنجره مـا اشلبهها،}

Another figure of speech to express amazement is used in the phrase ما اشلبها ma

ashlebha. The phrase شلبي comes from the شلبها cord اشلبه shalabi and is translated from Palestinian Arabic to mean "How beautiful [she is]" (أنيس 1990). This word is popular among SPA, and has been used in the famous song by Fairouz, “الثُلبيهalshalbiuh”. Within this context is used after the aforementioned phrase يخرب بيت yakhrub bayt "I'll be damned". Therefore, I would argue the use of اشلبها is what give the reader and listener enough contextual evidence to understand that the phase يخرب بيت is not an insult, but rather an extension to this term of amazement. ${ }^{19}$ However, when speaking MSA, my first instinct would have me use "جملها ma ajmalha, which also means "how beautiful".

\section{6. " فرحو فيها بلاييا.}

To add to the lexical inconsistencies between both languages -- the narrator of this story Says بلايا balaya, rather than using the MSA word كثير, meaning "a lot" and "greatly". The meanings are the same, however these two words do not share the same root, thus making it nearly impossible to determine the meaning without any supplemental material from the author of the text. In fact, the root comes from a MSA word بِليَّة baliyyah meaning “a disaster".

Considering how disasters are usually a "greater" version of a smaller issue, one might be able to understand how the word بلايا is used to mean "great" or "a lot".

\footnotetext{
19 The word ashleb is derived from the Turkish word “Çelebi”. Çelebi was a word used during the Ottoman Empire to mean "gentleman" or "honorific". Many notable people throughout history were known to have this as their surname; such as sons of Ottoman sultan Bayezid and Evliya Çelebi, which the sultan's paternal genealogy can be traced back to the imams of early Islamic history. Considering how Arabs were under Ottoman rule for several centuries, it is easy to see how both Arabic and the Turkish language influence one another.
} 


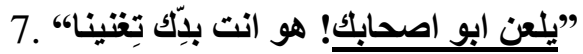

The common Palestinian phrase يلعن ابو اصحابك yal'an' 'abu ashabik (Ṣ-hāabik) is an idiomatic expression that denotes anger and cursing. Additionally, it is commonly used in other areas of the Levant and throughout the rest of the Arab world. This phrase translates to "damn the father of your owners". The root of the verb used is خرب kharaba, meaning "to curse", which can be interpreted as "to damn". Within the original Arabic text and the English variant, I found an interesting discrepancy with the word اصحابك ashaabik. In MSA, this word is the plural for "friend" and "owner" Given the context, owners make much more sense, and therefore we know it wasn't a translational error. However, from the perspective of a non-native Arabic learner, this would appear very confusing, linguistically. Socially, understanding why a person would curse another person's owner is also quite odd from the perspective of someone non-native to the specific culture. One could argue and analyze the fact that because the pot is a female in a male dominated society, one would damn those who maintain control. However, the origin of this phrase requires further research. For the non-native speaker, it is important to know the phrase is far heavier and more impactful in Arabic opposed to the English version as Muhawi clarifies in the footnotes.

\section{"8.}

Muhawi translated the word شَنتـه shanta as “a velvet dress". Muhawi mentions this replaces the MSA word for الثوبthobe, which holds the same meaning. This is very similar to the MSA word شنطة shanta which means "bag" or "luggage". Therefore, when reading the folktale, one could easily mistake the sentence for "she put on her velvet dress" for "she put on her bag”. Within SPA, this would be an elegant dress in which women will wear for special occasions such as a wedding. 


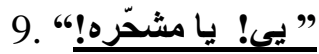

The phrase "مشَّره yaa mshahharah has an early pre-Islamic background relating to common practices that revolve around shame (Muhawi and Kanaana 1989) (Sbait 2017).

Whenever women were shamed, or ashamed of someone else, they would wear black, as this was also a sign of mourning. Women would additionally put dirt on their head, and put soot on their own face from charcoals. This act would be later known as مشَّره Masharah (Sbait 2017). The Word مشحِّره is the primitive process in which charcoal is made. Additionally, the one to process the charcoal would finish work and come out with a blackened face. Therefore, the process of putting the soot on one's face relates back to this example. The word has then evolved over time to become an insult or expression yelled at other people when they do a shameful act (as done in this story) (Sbait 2017).

Muhawi translates this in the English variant as "Yee, may your reputation be ruined". The word yee is a common expression in Arabic to denote exasperation. Again it is important to mention the weight in which idioms and curses hold in the Arabic language. These would not hold the same strength or impact when translated into English. Because of the uniqueness of this phrase, Muhawi adds the definition in the footnotes to further explain the usage of soot in correlation to mourning, and the importance of reputation and women within Palestinian culture..$^{20}$

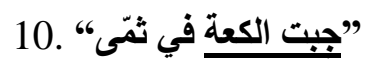

The next three phrases derive from baby talk and contain English similarities. There is a poetic function within this particular story which illustrates one of the main characters singing and using a rhyming pair to mean "In my mouth I brought the caca". The Palestinian word for

\footnotetext{
${ }^{20}$ Historically the Arab man would connect his honor with the woman of his family (Sbait 2017).
} 
caca shown in this text is الكّعله $k a^{c c} a$ and appears to be a cognate of the word "caca" aside from the second missing " $\mathrm{k}$ " sound. While reading this from the perspective of MSA, it is important to not get this word mixed up with the MSA word for "cake" كعكه/كيكة Kayka. This in turn, could result in further misinterpretations. Muhawi does give the reader some background about this word in the footnotes of the text.

\section{1. "21 "المعمعع"}

This word does not appear naturally in the folk narrative, but is used as a further example by Muhawi in the footnotes of the text as another word derived from baby talk. The word المعمع $m a^{c} m a$ is also a cognate and denotes the English word "mama". ${ }^{22}$ Muhawi and Kanaan mention the word "المعع") is also used for "meat" in colloquial speech. However, in MSA this word references the flesh in which would appear on the battlefield and used as a general term for war. This comes from the classical word المعمعه almaemaeuh, meaning "wars" or comes from the MSA word معمعان muemaean, which can mean "height, climax, raging, and turmoil", but can also be interpreted as “deep into battle” (Sbait 2017) (Almaany 2010-2017). The MSA word for meat is " لحم" lahem. However, an intellectual native-speaker of Arabic can easily comprehend the connection between "war" and "flesh" and by extension "meat" (Sbait 2017).

\section{2. “"النحة"}

The word النحة annaha does not find itself in this particular piece of the text, but rather in the footnotes as a description by Muhawi. This word is baby talk for anything sweet within SPA. According to the Almunjid Dictionary (a Palestinian dictionary), the word النحاء alnniha' can also

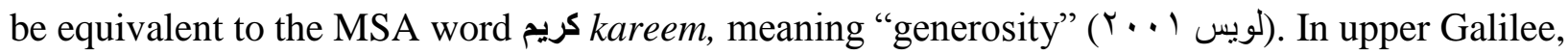
Palestinian mothers and babies use this spoken expression as محَّه mahha: it is used in reference

\footnotetext{
${ }^{21}$ The superscript $\mathrm{C}$ indicates the voiced Arabic letter " $\varepsilon$ " which does not exist in English.
}

22 The MSA variant of mother is $u m$. 
to candy (Sbait 2017). From my experience living in the Jordan, sweets would be quite popular throughout Ramadan, and among guests. Offering guests something sweet is a common act of kindness or generosity. This example provides linguistic evidence to further prove a deeper anthropological connection between the two meanings in Arab culture.

“Precious One and Worn-out One": الغالية والبالية) (v l)

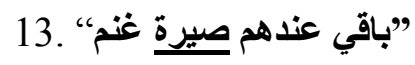

The word صيره seerah in this context is translated by Muhawi as "animal pen" ${ }^{23 "}$ and noted in the footnotes of the Arabic text that it contains the same meaning as حظيره hażeerah. The word حظيره can mean both, "animal pen" and "barn” in MSA. Even though صيره holds, a specific حظيره meaning pertaining to sheep; such as a "sheepcote" or "sheep pen". Muhawi uses the word hadheerah as a reference for those unfamiliar with the word صيره. My conclusion would be, that both words are Fusha Arabic (formal), however the word صيره is much more dated ${ }^{24}$. The word would then only be generally recognized among those who work with sheep; especially within the rural parts of Palestine, thus becoming part of Palestinian colloquial speech.

\section{4. لا يسهر تنّهِ اجا الغول}

The word تنّه tannuh is a Palestinian colloquial word for the preposition “until”. The MSA equivalent is حتى hatta or أنَّهُ annahu (Muhawi and Kanaana 1989) (Sbait 2017). This is noted by Muhawi in the text to aid unfamiliar readers of SPA. Because of its prepositional usage, there is not much to say in terms of Palestinian culture, however with a word so commonly used, it is important to be aware it's lexical attributes.

\footnotetext{
${ }^{23}$ Muhawi also then translates this word in English as "sheep pen" later in the text, after already using the phrase "animal pen" showing they are fairly synonymous with one another.

${ }^{24}$ The English equivalent "sheepcote" is chiefly British from the period in which late Middle English was used, 1375-1425 (Almaany 2010-2017).
} 


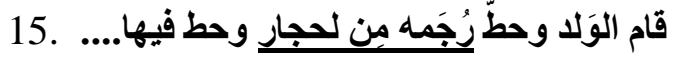

This phrase can appear very confusing due to differences between the literal translation in MSA and the intended meaning within Palestinian speech. This was translated as "heaped stones into a cairn" within the English translation of the text. This happens to be much different than the MSA translation. For example, according to Hans Wehr Dictionary, the word rujima means "tombstone" in MSA, which comes from the root رجم rajama 'to stone'. However, within the footnotes, Muhawi mentions this is used as the equivalent of the MSA word كومة (kawma), which means 'pile' or the verb كوم kawwama "to heap" or "to make a pile of stones" (Sbait 2017). So, within this context, there is a colloquial occurrence using the words "to stone something" in lieu of "to pile". In addition to the diglossia confusion; within the Arabic text, the preposition مِ min was left out. This was due to Muhawi's transcription from the original Palestinian narrator of the story. Both of these qualities can make the overall understanding of the occurrences in this part of the story very unclear to the non-native reader.

\section{6. نادي اخوتي وتعال نروح اوزّيكمِ ايّاه}

Often times within colloquial languages, morphological and phonological changes occur to make the word look and even sound different from the original MSA word. Within the text, the SPA word أورَّيكم awarreekum is demonstrated. This is a phonological change from the MSA word أرّيكم aureekum. This particular demonstration of Arabic diglossia does not change the overall meaning of the word, but shows how subtle differences in pronunciation occur between different Arabic languages. Additionally, this particular word is derived from ر ra'aa, which is the MSA verb for "to see". However, the verb form within the colloquial counterpart creates the meaning "to show". Some speakers of the Palestinian Spoken Arabic, alter it to روَّرو ruwarru and others use it as it as وَرحى waraha (Sbait 2017). Additionally, some of those who reside in the 
city may use the term فَجْْ farja (Sbait 2017). This is a prime example of different dialects within the Spoken Palestian Arabic Language, which may add further confusion upon the nonnative Arabic learner.

\section{7. انو بدّه يطيح منكم؟}

Muhawi translates this particular phrase as "which one of you will go down in this well?"

However, the word إنّ innuh, is a blend of two words in MSA إنَّ هو inna huwa, which come together to mean the phrase "the person who..." Given Muhawi's translation, it appears انو can also mean 'which' within the right context. Phonetically however, this word is very similar to the word انه annuh which means 'that he/it'. The second word in this phrase baddoh is commonly used throughout the Arab world, meaning "to want". The MSA equivalent to this word is related to the noun ودّ wad "like or love" and the verb بودّدي bawudee, meaning "I would like to". Over time, the verb got shortened which left the remaining sounds بدّه baddoh.

\section{8. قاللهن: "وقتيش بيجي هاظ الغول}

The word وقتيشwa 'taysh means 'what time' in SPA. This word is the product of what linguists call 'blending' or combining two words. The example here, is the combination of the words: وقت wa 'at denoting 'time' and ايش aysh denotating 'what', in order to form the phrase 'what time'. The word ايش is the Palestinian word denoting 'what', which has the MSA equivalent to "which" or "what" أي 'ay. The blended word of وقتيش demonstrates how the Palestinian word for 'what' can be used within a broader spectrum for the sake of ease in colloquial speech. It can be used in many contexts, including time. As aforementioned, when describing the phrase يمرقو is the word وقت , the morphologically between SPA and MSA, ${ }^{25}$ but is different phonetically. Colloquial spoken words containing the letter قqaf can be

\footnotetext{
${ }^{25}$ See 4 above.
} 
pronounced differently, given the geographical region, ethnic group, or community in which it is told. For example, the majority of Palestinians people from southern Lebanon may pronounce the af as a glottal stop or 'hamza', opposed to how the older generations of Druze and Bedouin tribes use the heavier sounding ق (qaaf), similar to the phonetic ' $q$ ' or ' $g$ ' in English. 19. فات بتخبا في قوس الحوايج لاقا هالسيف

The phrase قوس الحوايج qoos alhawayij is used among Palestinians to mean the "arch for bedding" but is translated within the English copy as 'recess in the wall' in order to bring more clarity among English readers. Within the footnotes of the Arabic copy, this phrase is expounded upon further as: "In the thick walls of the old Palestinian houses, the builders made a space in the form of an arch to keep the mattresses and their covers and some clothes behind a curtain that fell during the day" (Muhawi and Kanaana 1989). ${ }^{27}$ The word قوس qoos can mean "arch" in MSA and Palestinian Arabic alike. Whereas, the word الحوايج alhawayij is a clear result of Arabic diglossia. The word الحوائج comes from the classical word الحوايج alhawa'ij. ${ }^{28}$ In the context of this Palestinian folk narrative, the word الحوايج means 'needs', juxtaposed to the word 'الفراش' alfarash, which is commonly used in MSA and several other Arabic languages and dialects (Wehr 1994). Even among native Arabic speakers, understanding the phrase قوس الحوايج may still appear confusing without a full understanding of the cultural significance since it may mean "the arch where various items needed around the house are kept" (Sbait 2017). Therefore, among non-native Arabic learners, this phrase is much harder to understand, due to its classical roots, and cultural complexities.

\footnotetext{
${ }^{26}$ See footnote 19 and Appendix B.

27 The translation used within the English copy appears as the 'recess'. The latter half of the phrase 'in the wall', is left out and implied, due to the usage of the entire phrase 'recess in the wall', which is used a few sentences prior in the text.

${ }^{28}$ Hans Wehr dictates that the word الحوائج is "anomalous" therefore locating its definitive meaning in Classical Arabic is much more difficult. This word is thought to have come from the root حاج. See (Wehr 1994) for a morefull and in-depth etymological overview of this word.
} 


\section{"إصْحكث تظربه إلا تثوف عينيه حمر لعنّه ببقى نايح." .20}

Within this sentence, the phrase لعنّه ببقى نايم leannu bibqa naayim is used. The Palestinian denotation of this phrase is "[because] he [remains] is asleep" 29 . However, if one were to look at this phrase with only MSA comprehension, then this could be roughly translated as "damn him, he remains asleep". The reason for that being has to do with two key words: لعنّه leannahu and بيقڤى.bibqa. The word لعنّه is phonetically changed from MSA by the narrator of the folktale, due to their colloquial background. For example, in MSA, the equivalent is le 'annu, meaning "that he" or "because he". This example shows the letter I $A A$ changed to the letter $\varepsilon$ a ${ }^{c} y n .{ }^{30}$ In MSA, the word بيقى bibqaw means "stayed" and comes from the root بقي baqi meaning "to remain". However, in the context of this Palestinian folktale, this word means "to be" as in "he is

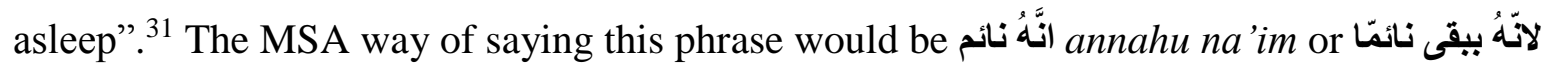
leannahu bibqa na'ima, "for he remains asleep".

\section{"اذا بيقى غير هيذا إوعاتظربه، ..." .21}

The analysis within this particular phrase is more linguistically noteworthy than cultural. The word إوعا awuac is a common Palestinian phrase to mean "watch out "or "be careful". It typically has a direct object after it, further denoting what to watch out for specifically.

According to Muhawi, the MSA equivalent is إحْذَّ ihdhar meaning "be careful” or انتبَه ntabuh, meaning "watch out" (Almaany 2010-2017). ${ }^{32}$

Additionally, this sentence contains the word هيذا haydha which contains a phonetic alteration known as epenthesis and derives from the MSA word for /

\footnotetext{
${ }^{29}$ The words "because" and "remains" were not present in the English translation.

${ }^{30}$ See footnote 20.

${ }^{31}$ Emphasis added on $i s$.

32 Within the footnotes, Muhawi and Kanaana choose a different word as the MSA equivalent, حذار meaning

"beware". In this case إحْذَ is the fourth form of the same verb as is more a appropriate alternative for this context.
} 
Epenthesis is a key function and definitive description of Arabic diglossia which adds a syllable to a word creating a different sound. Sometimes within colloquial speech, this can allow speakers to create better speech more in line with their spoken Arabic. This can also change the original pronunciation of a single letter (Sbait 2017).

22. "كل يوم بنام على إجرٍ

The SPA word إجر ijr is typically used in Palestinian Arabic for "leg" or "foot", opposed to the MSA meaning for leg, which is ساق saq. However, in this context, the word إجرis actually referencing someone's lap. Whereas the meaning for lap in MSA is حضن hudn. Additionally, there is another word for leg or foot in MSA known as رجلrjl.33 It is important to understand these differences in both Palestinian Arabic and MSA or one could risk mistranslating either intention. For example, the Palestinian variant could be mistaken with words derived from the root ajr, meaning “to reward”, “wages”, "pay”, etc. (Wehr 1994).

This example merely shows a glimpse into how versatile, and multifaceted words in the Arabic Language can be. From the non-native perspective, understanding both Palestinian Arabic juxtaposed to MSA is a challenge. This can be used as an introduction for preparing to acknowledge linguistic and cultural overlapping within the other spoken Arabic languages and dialects that exists beyond SPA and MSA.

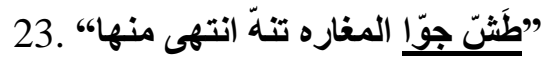

The phrase جَشّ جوّا tush juwwa is translated as "he wandered around inside" (Almaany 2010-2017). Muhawi and Kannana make note that, the MSA equivalent is تجوّلَ فيها tajawwala feeha. This term is related to the word الطيّاش attyash, meaning someone who is "spacey" therefore does not commit to a specific direction (Sbait 2017). The root طشّ tash appears to be

\footnotetext{
33 The word زلم zelameh is another common word for "man" in Palestinian Arabic. I found it interesting, that if one were to replace "man" with "lap" within the context in this particular passage, it would still make sense.
} 
related to the MSA root طاش taash, whereas the active participle طائش tayish means "aimless", “desultory", "random” or "stray" (Almaany 2010-2017).

"24بِّه يتجوز البنت الزغيره والبنت معيّيه تتجوّز إلا غير تنه...، .

Muhawi translates the word معيّيه macayih as "refuse" in the English translation; the MSA equivalent comes from a blend of two words: the preposition maac, denoting "with", which is prefixed to the verb عيّي $a a^{c} e e$, meaning "handicapped" or "to be incapable of" (Almaany 2010-2017) (Sbait 2017). As a non-native speaker, the word عيّي may be troublesome due its lack of commonality. Therefore, when seen within colloquial contexts, it can be difficult to recognize. The word itself presents more of a linguistic challenge, opposed to potential cultural misinterpretations.

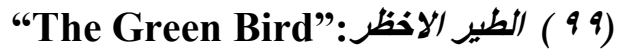

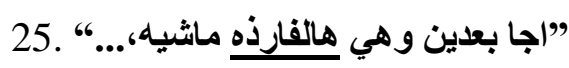

The phrase هالقارذه ماشيه halfardih mashyee means the "wedding procession is going” in SPA and is derived from literal MSA words. For example, هال is a colloquial blend of the MSA

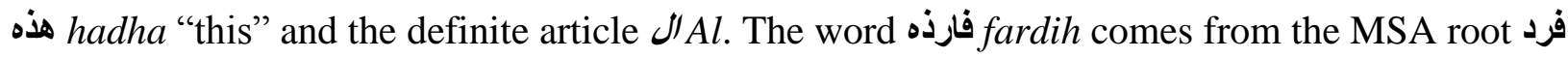
frd, which means 'individual'. However, in this context, فارذه is a noun and denotes a group of people whom are delegates to the groom. These people are typically the groom's parents and are the ones to address the bride's family with regards to wedding proposals (Sbait 2017). Part of the celebration of the wedding involves moving the bride from the bride's home to the groom's home, typically in a large caravan. This is known as the فارذه (Sbait 2017). Lastly the word ماثشيه mashyyeh, comes from the MSA verb مشى masha "walking" (Wehr 1994). Therefore the literal phrase means "this delegation was walking". According to Ibrahim Muhawi, the MSA equivalent 
of this entire phrase is موكب الزفافmawkib azafaaf juxtaposed the exact literal usage in which the narrator of the story chose to use. ${ }^{34}$

"وفِ لك روحي نادي عاخولِ بِيع.."

The meaning of the word بسيع biseea ${ }^{c}$ contributes to another lexical difference between MSA and SPA. In SPA the word بسيع means "quickly", however if we were to say this in MSA, one would use the phrase بسرعه basurac (Wehr 1994). However, the word بسيع biseeac actually derives from the MSA phrase بهذه الساعة bihadhih assaeac which means "this time" and connotes “quickly" (Sbait 2017). Therefore the word بسيع is another blend of two MSA words in which make it very difficult to understand the origin and meaning of the word.

"27. "اسا خالتكو بتصير تقتلكو."

This phrase contributes to Arabic diglossia in a unique way, rather lexical differences between MSA and PSA, this word creates problems for the non-native Arabic learner with regards to semantics and pragmatics and the social context in which it is used. The translation of the SPA word خالتكو khalitku means "your maternal aunt" in English. The head of this word $i s$ خاله khala, which means maternal aunt, with a plural possessive suffix $k u$ attached. In this context, the widowed father is talking to his two kids about their female neighbor. The entire phrase translates to, "if I get married now, your aunt will beat you". He is not referring to their actual aunt, but rather their neighbor (with whom they want him to marry).

The cultural implications here illustrate how, close friends of the family, respected elders, or even step parents are referred to as 'aunt' and 'uncle'. This is strikingly different in the

\footnotetext{
${ }^{34}$ Ibrahim Muhawi mentions in the footnotes of this folktale that this word is equivalent to موكب الزفاف, however الفارده is actually a part of بوكب الزفاف which really means "wedding party".

${ }^{35}$ Colloquial expressions typically deleted the letter 2 within the possessive affix instead.
} 
western word. When people get remarried, it is not uncommon for their kids to call ones newly acquainted spouse 'mother' or 'father'. Therefore when reading this literally, a non-native Arabic learner, or someone unfamiliar with Palestinian or Arab culture, would misinterpret this phrase. This act was derived from biblical practices of men marrying the sister of their wife (if she accepts) if their wife were to die. The mindset was in the best interest of the orphans, that way they were already comfortable with their father's new spouse (Sbait 2017). The term خاله was then extended to any other stepmother as well (Sbait 2017).

\section{Conclusion}

This paper demonstrates the historical context of Arabic, educational complications which arise from Arabic diglossia, and emphasized crucial differences between Modern Standard Arabic and the Spoken Palestinian Arabic language. The complex language variations of Arabic illustrate the multifaceted dimensions that Arabic diglossia imposes. This exemplifies the complications presented by Ferguson ${ }^{36}$ and reaffirm Fishman's definition that people themselves cannot be classified as diglossic, but is rather identified by the behavior of the speech community in which they are in, and that more than two varieties can be used. This particularly was demonstrated throughout the analysis when describing the letter and how this letter is pronounced very specifically based on multiple social contexts.

Linking societal and linguistic dimensions in the analysis of SPA words and phrases were important for achieving a deeper understanding of Muhawi and Kanaana's anthropological Analysis and SPA language. By comparing SPA with its MSA counterpart, deeper cultural conclusions were made. One primary example mentioned in the analysis, is the duality of meaning and etymology of the word نحة. This word is baby talk for sweet, however its origin

\footnotetext{
${ }^{36}$ Functions, prestige, literary heritage, acquisition, standardization, stability, lexicon, and phonology. It is worthy to note that Ferguson's points are generalized and call for a more narrowed focus of the Arabic language.
} 
comes from the word "generous". This shows linguistic evidence of how sweets can play a role within Palestinian society and possibly importance behind them.

The work put forth by Ibrahim Muhawi and Sharif Kanaana undoubtedly contributes to the preservation of both the Palestinian culture and way of life. The existence of Speak Bird, Speak Again effectively supports the idea that language is certainly an utmost fundamental aspect of culture. Therefore, the sociolinguistic approach put forth in this paper was able to add to Muhawi and Kanaana's commentary in a way that was not necessarily presented before. After considering the lack of literature regarding Arabic diglossia from the perspective of a non-native learners, I conclude that analyzing Arabic diglossia by relating linguistic components with cultural-specific characteristics can aid in the cultural and linguistic comprehension process of non-native Arabic learners.

From my research, Arabic diglossia appeared to be one of the most common linguistic terminologies mentioned with regards to the Arabic language. With that being said, one can still apply Arabic diglossia to many new studies and approaches. Throughout my paper I focused the perspective of the non-native Arabic learner, such as myself. Therefore, I decided to only look at the differences between Modern Standard Arabic and the Spoken Palestinian Arabic language because of its prevalence and impact among non-native learners. Aforementioned studies in this paper mention the struggles among native Arabic speakers with MSA based on the differences of their own spoken variation. However, I would propose someone take a different approach. Rather than comparing the SPA to MSA, I would recommend comparing SPA to another Spoken colloquial language as well, such as Egyptian Arabic, or Gulf Arabic. The implementation of MSA would still have to be available, due to many classical origins. If this was to be done, it 
would contribute to the clarification and transparency of SPA to other native speakers who might have a hard time understanding Palestinian folk narratives, in particular. 


\section{Bibliography}

Alan S. Kaye, Fullerton. 1994. "Formal vs. Informal in Arabic: Diglossia, Triglossia, Tetraglossia, etc., Polyglossia-Multiglossia Viewed as a Continuum ." Zeitschrift für Arabische Linguistik 47-66.

Almaany, SanJeem. 2010-2017. الsعاني Almaany.com.

Al-Mamari, Hilal. 2011. Arabic Diglossia And Arabic As a Foregn Language. Muscat, Oman: SIT Graduate Institute/SIT Study Abroad.

Eid, Mushira. 1996. Perspectives on Arabic Linguistics. Amherst, Massachusetts: John Benjamins Publishing. Accessed May 08, 2017. https://books.google.com/books?id=cpBAAAAQBAJ\&dq=is+Arabic+diglossia+synchronic+or+diachronic\&source=gbs_nav links_s.

Ferguson, Charles A. 1959. "Diglossia." WORD 325-340.

Fishman, Joshua, A. 1967. "Bilingualism With and Without Diglossia; Diglossia With and Without Bilingualism." The Society for the Psychological Study of Social Issues (Blackwell Publishing Ltd) 23: 29-38. Accessed May 08, 2017. doi:10.1111/j.15404560.1967.tb00573.x.

Hudson, Alan. 2002. "Outline of a theory of diglossia." Int'l. J. Soc. Lang 1-47.

Ibrahim Muhawi, Edinburgh. 1998. "Between Translation and the Canon: The Arabic Folktale as Transcultural Signifier." Fabula 105-118.

Kanaana, Sharif. 2005. "The Arab Ear and the American Eye: A Study of the Role of the Senses in Culture." (The University of California) 4: 29-45.

Karateke, Hakan. 1998. University of Chicago. https://ottomanhistorians.uchicago.edu/en.

Klaus Roth, Munchen. 1998. "Crossing Boundaries: the Translation and Cultural Adaptation of Folk Narratives." Fabula 243-255.

Maamouri, Mohamed. 1998. Arabic diglossia and its impact on the quality of Eduaction in the Arab Region. Philadelphia: International Literacy Institute.

Mahmoud A. Al-Sobh, Abdel-Rahman H. Abu-Melhim, Nedal A. Bani-Hani. 2015. "Diglossia as a Result of Language Variation in Arabic: Possible Solutions in Light of Language Planning." Journal of Language Teaching and Research (Journal of Language Teaching and Research) 274-269. 
Muhawi, Ibrahim, and Sharif Kanaana. 1989. Speak Bird Speak Again. Los Angeles: Regents of the University of California.

Owens, Jonathen. 2001. "Arabic Sociolinguistics." Arabica (Brill) 419-469.

Rosenhouse, Judith. 2011. "Trends of Development in Arabic Dialcetology in the 20th Century: A Survey." Zeitschrift für Arabische Linguistik 42-66.

Rynolds, Dwight F. 2009. Epic and History in the Arabic Tradtion. London, New York: WileyBlackwell.

Sbait, Dirgham H., interview by Jordan Martinez. 2017. Class Instruction Portland, Oregon, (April 11).

Tiedemann, Fridrik E. 2015. The 101 Most Used Verbs in Spoken Arabic: Jordan and Palestine. Primedia E-launch LLC, 2015.

Wehr, Hans. 1994. Arabisches Worterbuch fur die Schriftsprache der Gegenwart. 4. Edited by J Milton Cowan. Spoken Language Services.

$$
\text { لويس, فريحا، .1990 بُعجم العامبه اللبنانبه يبيروت: مكتبة لبنان. }
$$




\section{Appendix A. English Translation--Palestinian Arabic Chosen Words in "Speak Bird..."}

\section{Tunjur, Tunjur (pg. 55)}

1. "She had an urge, she wanted babies..." May Allah grant me a child even if it is a cooking pot" (pg. 55)

2. "The pot started to roll" (pg. 56)

3. "I'll be damned, what a beautiful pot! (pg. 56)

4. "In a while, people were passing by." (Pg. 56)

5. " How beautiful this pot! (pg. 56)

6. "The whole family was greatly pleased with it." (pg. 56)

7. "Damn your owners! He cursed the Pot. Did you think you were going to make us wealthy?" (Pg. 56)

8. "She put her velvet dress on and brought the pot out..." (Pg. 58)

9. "Yee! May your reputation be blackened! She cried out." (Pg. 59)

10. "In my mouth, I brought the caca...." (Pg. 59)

11. "mac $\mathrm{ma}^{\mathrm{c} "}$ (Pg. 56-foot notes)

12. "Naha" (Pg. 56-foot notes)

Precious One and Worn-out One (pg. 62)

13. "They had an animal pen..." (Pg. 62)

14. "...he stayed awake until the ghoul came" (Pg. 63)

15. "The youth heaped stones into a cairn." (Pg. 63)

16. "Call my brothers together and let's go to his place, I'll show you where it is." (Pg. 63)

17. "Which one of you is going to go down into this well?" (Pg. 63)

18. "When does this ghoul come back?" (Pg. 64)

19. "Going to hide into the recess [in the wall] the youth found a sword."(Pg. 64)

20. "That's the only way you can be sure he is asleep." (Pg. 64)

21. "... be careful not to strike." (Pg. 64)

22. "Every night he sleeps in one of our laps." (Pg. 64)

23. "He wandered around the inside of the cave until he came to the end of it." (Pg. 65)

24. "He wanted to marry the youngest girl but she refused to marry him until..." (Pg. 65)

The Green Bird (pg. 98)

25.'If I get married now your aunt will beat you" (pg. 98)

27. Hey you, go call your brother right away." (pg. 99)

26. "In a while, as the wedding procession moved along..." (Pg. 101) 


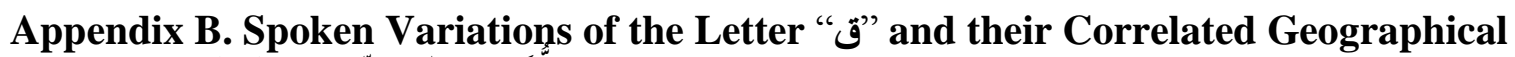

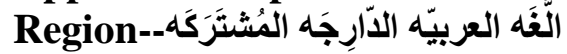

'To be able to' ( Spoken Arabic): قدر

'To be able to' (MSA-Fusha): قدر :على

\begin{tabular}{|c|c|c|c|c|c|}
\hline Region & Pronunciation & Letter & Future Tense & $\begin{array}{r}\text { Present } \\
\text { Tense }\end{array}$ & Past Tense \\
\hline MSA & ق & ق & راح اقَّرَ & بَقِّر & قِِِرْت \\
\hline Lebanon/Egypt & $\varepsilon$ & ق & أَأدَر & بأدر & إدرت \\
\hline Bedouin/Gulf & g & ق & $\mathbf{X}$ & بَجْْْر & جُـْرَت \\
\hline / عامّه /Bedouin & ج & ق & $\mathbf{X}$ & بجدر & جلرت \\
\hline / عامّه & $\bar{\varepsilon}$ & ق & $\mathbf{X}$ & بغلر & غدرت \\
\hline $\begin{array}{l}\text { Only In the } \\
\text { Nazareth Galilee } \\
\text { Region }\end{array}$ & ك & ق & $\mathbf{X}$ & بكلر بـ بكر & كلرت \\
\hline
\end{tabular}

(C) (Sbait 2017) 